2013-01

\title{
Accumulation of Aqueous and Nanoparticulate Silver by the Marine Gastropod Littorina littorea
}

\author{
$\mathrm{Li}, \mathrm{H}$
}

http://hdl.handle.net/10026.1/3923

\subsection{7/s11270-012-1354-7}

Water, Air, \&amp; Soil Pollution

Springer Science and Business Media LLC

All content in PEARL is protected by copyright law. Author manuscripts are made available in accordance with publisher policies. Please cite only the published version using the details provided on the item record or document. In the absence of an open licence (e.g. Creative Commons), permissions for further reuse of content should be sought from the publisher or author. 


\title{
Accumulation of Aqueous and Nanoparticulate Silver by the Marine Gastropod Littorina littorea
}

\author{
Haiying Li • Andrew Turner • Murray T. Brown
}

Received: 17 April 2012 / Accepted: 6 November 2012

(C) Springer Science+Business Media Dordrecht 2012

\begin{abstract}
The accumulation of Ag by the marine herbivorous gastropod, Littorina littorea, has been studied in a series of exposures in which the metal was added in aqueous form and as nanoparticles, both in the presence and absence of contaminated algal food (Ulva lactuca). Significant accumulation occurred in the gill, kidney, stomach and visceral mass when the snail was exposed to aqueous Ag in the absence of food. Despite the consumption of $U$. lactuca that had been previously contaminated by $\mathrm{Ag}$, no accumulation was observed from the dietary route. When added as nanoparticles, accumulation of Ag was only measured in the head and gill and only in the absence of contaminated food. These observations suggest that $\mathrm{Ag}$ is most bioavailable to $L$. littorina when in true solution and that $\mathrm{Ag}$ measured in external tissues of the snail following exposure to nanoparticles arises from some physical association that does not result in significant transfer of the metal to internal organs.
\end{abstract}

H. Li • A. Turner $(\bowtie)$

School of Geography, Earth and Environmental Sciences, University of Plymouth,

Drake Circus,

Plymouth PL4 8AA, UK

e-mail: aturner@plymouth.ac.uk

\section{T. Brown}

School of Marine Science and Engineering, University of Plymouth,

Drake Circus,

Plymouth PL4 8AA, UK
Keywords Silver Nanoparticles · Marine · Accumulation $\cdot$ Littorina littorea $\cdot$ Ulva lactuca

\section{Introduction}

The rapidly developing and evolving areas of nanoscience and nanotechnology have resulted in an increase in both the production and diversity of nanomaterials in recent years. Engineered nanoparticles represent a bridge between bulk material and structures at the atomic or molecular level and have important roles in the medical, cosmetic, pharmaceutical, energy, remediation, electronics, textile, plastics and food industries (Nowack and Bucheli 2007). In concert with their increasing production, increasing quantities of nanoparticles are entering the environment during their synthesis and during the manufacture, usage, disposal, and recycling of products that contain them (Köhler et al. 2008). Because of their small size, large surface area and high reactivity and mobility, concern has been levelled at the impacts of engineered nanoparticles on human health and their biogeochemical behaviour and toxicity in the environment. In aquatic systems, where many contaminants ultimately reside, nanoparticles may be directly and/or indirectly toxic. Direct effects arising from the high density of reactive groups at the nanoparticle surface include damage to cell membranes (Zhu et al. 2008; Hao et al. 2009), while indirect effects result from the production of reactive oxygen species and dissolution 
of toxic ions or impurities into solution (Blinova et al. 2010; Park et al. 2011).

Because of their antibacterial effects, chemical stability and relatively low cost of production, silver nanoparticles (AgNP) are among the fastest growing and most commercialised groups of engineered nanomaterials (Fabrega et al. 2011). However, because of the high toxicity of $\mathrm{Ag}$ to aquatic organisms and the propensity of the metal to bioconcentrate (Luoma et al. 1995), they also rank among the nanoparticles of greatest environmental concern. The precise proportion of total Ag currently entering the aquatic environment as nanoparticles is unclear, but recent estimates suggest a figure of around $15 \%$ and indicate a future, exponential increase (Blaser et al. 2008; Gottschalk et al. 2009).

Despite concerns about AgNP, there have been relatively few studies of their interactions with and toxicities to aquatic organisms. Moreover, the modes of action and accumulation are often unclear and appear to be organism specific, with some studies implicating the nanoparticles themselves (e.g. Asharani et al. 2008) and others the $\mathrm{Ag}^{+}$ion that is mobilised from the particle surface (e.g. Bilberg et al. 2010). In sea water, studies of the behaviour of AgNP are very limited, with observed effects and accumulation in microalgae and macroalgae attributed to the dissolution of $\mathrm{Ag}^{+}$(Miao et al. 2009; Turner et al. 2012) and the mode of toxicity to oyster embryos undefined (Ringwood et al. 2010).

In the present study, and to improve our understanding of the behaviour and effects of AgNP in the marine environment, we examine the accumulation of Ag by the herbivorous gastropod, Littorina littorea, a common inhabitant of rocky shores throughout northwest Europe and the north Atlantic coast of America. Snails were exposed to aqueous and nanoparticulate forms of the metal, both in the presence and absence of the green macroalga, Ulva lactuca, as a source of precontaminated food. Accumulation is determined in different organs of the snail and in faecal matter generated during the exposures.

\section{Materials and Methods}

\subsection{Samples and Reagents}

Plasticware used in the experiments and for sample digestion was soaked in $0.5 \mathrm{M} \mathrm{HCl}$ for $24 \mathrm{~h}$ and rinsed three times with distilled water before being used.
Containers for analyte storage were purchased from Fisher Scientific and were used without being cleaned. English Channel sea water (salinity $=32.5 ; \mathrm{pH}=8.0 \pm$ 0.2 ; dissolved organic carbon $\sim 100 \mu \mathrm{M}$ ) used for culturing and experimental work was available on tap in the laboratory after online filtration through a $0.6-\mu \mathrm{m}$ extruded carbon filter. Aristar-grade silver nitrate solution $\left(\mathrm{Ag}=10,000 \mathrm{mgL}^{-1}\right)$ was obtained from BDH-VWR and silver nanoparticles of $<100 \mathrm{~nm}$ in diameter were purchased as a powder from SigmaAldrich (product number 576832-5g; batch number $07721 \mathrm{KH})$. The purity of the particles was stated as $>99.5 \%$, and surface area was reported as $5.0 \mathrm{~m}^{2}$ $\mathrm{g}^{-1}$. Other reagents employed in the study were purchased from Fisher Scientific or BDH-VWR and were of analytical grade or equivalent.

Immediately before being used in the experiment, a $10-\mathrm{mL}$ working stock solution of $100 \mathrm{mgL}^{-1}$ $\mathrm{AgNO}_{3}$ was prepared by appropriate dilution of the original standard in Millipore Milli-Q water (MQW). A $1,000 \mathrm{mg}^{-1}$ stock suspension of AgNP was prepared by adding $10 \mathrm{mg}$ of AgNP to $10 \mathrm{~mL}$ of MQW in a $25-\mathrm{mL}$ polyethylene centrifuge tube and, to effect dispersion, sonicating the contents in a Sonicleaner bath (Lucas Dawe Ultrasonics) for $1 \mathrm{~h}$ (Bradford et al. 2009).

Samples of $U$. lactuca and L. littorea (of columellar height $\sim 2 \mathrm{~cm}$ ) were collected from the intertidal rocky shore at Wembury, a protected beach $7 \mathrm{~km}$ to the south east of Plymouth, UK, during September and October, 2010. Samples were transported in zip-lock plastic bags containing native seawater to the laboratory where they were cleaned of particulate matter and epibionts under laboratory sea water. Cleaned algal samples were transferred to a series of 10 -L clear Perspex aquaria supplied with aeration and maintained in a culture room at constant temperature of $14 \pm 1{ }^{\circ} \mathrm{C}$ and under fluorescent lighting $(250 \mu \mathrm{mol}$ $\mathrm{m}^{-2} \mathrm{~s}^{-1}$ photosynthetic active radiation for $12 \mathrm{~h} /$ day). As required, 9-mm diameter discs ( $\sim 6 \mathrm{mg}$ dry weight) were cut from the central portions of individual thalli using a plastic cork borer and acclimatised in an aquarium with clean sea water for 5 days under the conditions described above. Cleaned individuals of $L$. littorea were acclimatised, and their guts voided in a separate aquarium for a period of 10-15 days. No shedding of cercariae was evident, and individuals were therefore assumed to be uninfected by trematodes. 


\subsection{Size Characterisation of AgNP}

Considering the importance of their size and aggregation behaviour in environmental studies (Mackay et al. 2006; Carlson et al. 2008), nanoparticles in the stock and experimental medium were characterised by nanoparticle tracking analysis using a Nanosight LM10 instrument. Thus, quadruplicate $1-\mathrm{mL}$ aliquots abstracted from the surface of the stock immediately after sonication and in sea water that had been amended with AgNP at concentrations ranging from 1 to $10 \mathrm{mgL}^{-1}$ (verified by subsequent chemical analysis; see below) were introduced individually into the viewing chamber of the instrument where particles were video-tracked for a period of $90 \mathrm{~s}$. Data were acquired and analysed using the accompanying software.

The results of this exercise revealed an average nanoparticle size ( \pm one standard deviation) in sea water of $58 \pm 27 \mathrm{~nm}$. This is close to the mean particle size measured at the surface of the original stock suspension where we abstracted for experimental purposes $(45 \pm 33 \mathrm{~nm})$ and to the mean size of particles measured independently and ex situ by transmission electron microscopy $(59 \pm 19 \mathrm{~nm}$; Bradford et al. 2009). This suggests that, under the experimental conditions employed in the present study, little aggregation of particulate Ag occurs. We note that aggregation of AgNP added to artificial sea water (albeit at an unspecified concentration) is reported by Miao et al. (2009), but surmise that better dispersion of a lower concentration of nanoparticles in our experiments is effected by the presence of natural polyelectrolytes.

\subsection{Experimental}

The exposures were performed over a period of 5 days in individual 2-L Perspex aquaria, each containing $1.5 \mathrm{~L}$ of laboratory sea water and under the conditions described above. Three different treatments were undertaken after the addition of either $150 \mu \mathrm{L}$ of $\mathrm{AgNO}_{3}$ stock (nominal concentration of $\mathrm{Ag}$ of $10 \mu \mathrm{gL}^{-1}$ ) or $30 \mu \mathrm{L}$ of $\mathrm{AgNP}$ stock (nominal concentration of $\mathrm{Ag}$ of $20 \mu \mathrm{gL}^{-1}$ ); there were eight replicates of each treatment and five controls in the absence of added silver. [Note that different nominal concentrations of aqueous and nanoparticulate $\mathrm{Ag}$ were employed to ensure similar absolute concentrations by the end of the time courses (see below).]

In treatment 1 (T1), L. littorina were exposed to contaminated sea water by adding an individual to each aquarium $(n=8)$ after a period of 5 days. After a further 5 days, snails were retrieved, rinsed in distilled water and stored frozen. Faeces remaining in each aquarium were pipetted into a $25-\mathrm{mL}$ polyethylene centrifuge tube and the pooled contents vacuum filtered through a $0.45-\mu \mathrm{m}$ Whatman membrane filter. Filters were rinsed with MQW and subsequently frozen pending freeze-drying, digestion and analysis (see below). At daily intervals during the exposure, $1 \mathrm{~mL}$ water samples were abstracted from each aquarium, diluted tenfold in $0.1 \mathrm{M} \mathrm{HNO}_{3}$ in $25 \mathrm{~mL}$ centrifuge tubes and stored in the dark pending analysis (see below).

In treatment 2 (T2), individuals of L. littorina were exposed to contaminated sea water and contaminated food. Thus, the treatment and sampling proceeded as above but, additionally, four discs of $U$. lactuca were added to each aquarium immediately after the addition of $\mathrm{AgNO}_{3}$ or AgNP. One disc per aquarium was retrieved after 5 days, and before the introduction of the snail, and was rinsed with MQW and stored frozen pending freeze-drying, digestion and analysis (see below); algae remaining at the end of the treatment were pooled and processed likewise. In treatment 3 (T3), L. littorina were exposed to contaminated food and clean sea water. Here, four algal discs were incubated in each of eight aquaria containing sea water contaminated with either $\mathrm{AgNO}_{3}$ or AgNP, while snails were kept in aquaria containing clean sea water. After 5 days, one disc of $U$. lactuca from each aquarium was sampled and frozen, while the remaining discs were added to the clean aquaria housing snails and the contents of these aquaria incubated for a further 5 days before snails, residual algae and faeces were retrieved and frozen.

\subsection{Sample Digestion}

After snails were partially defrosted, their shells were cracked in a small bench vice. Animals were then carefully retrieved using plastic tweezers and dissected using a stainless steel scalpel. Thus, the head, foot (including the operculum), gill, kidney, stomach and visceral complex (including the digestive system and gonads) were excised from each snail and stored frozen and individually in ziplocked bags. Tissue samples, individual and residual discs of $U$. lactuca and pooled faeces were then 
freeze-dried for $48 \mathrm{~h}$. Dried samples were weighed into individual 4-mL screw-capped Teflon beakers and microwave-digested for $45 \mathrm{~min}$ on a series of hot-cool cycles in $2 \mathrm{~mL}$ of $\mathrm{HNO}_{3}$ using a CEM MDS-2000 microwave digester. The residual contents of each beaker were transferred to individual $25 \mathrm{~mL}$ polyethylene centrifuge tubes and diluted to $10 \mathrm{~mL}$ with MQW. Procedural blanks $(n=12)$ were undertaken likewise but in the absence of solids.

\subsection{Sample Analysis}

Acidified sea water samples and $\mathrm{HNO}_{3}$ digests of faeces, $U$. lactuca and tissues of L. littorina were analysed for $\mathrm{Ag}$ (as ${ }^{107} \mathrm{Ag}$ ) by quadrupole inductively coupled plasma-mass spectrometry (ICP-MS) using a Thermo Scientific X Series II bench top instrument (Hemel Hempstead, UK) fitted with a concentric glass nebuliser and conical spray chamber with impact bead. Forward power was set at $1.4 \mathrm{~kW}$, coolant gas flow was $13 \mathrm{Lmin}^{-1}$, auxiliary gas flow was $0.7 \mathrm{Lmin}^{-1}$, nebuliser gas flow was $0.86 \mathrm{Lmin}^{-1}$, and dwell time per mass was $10 \mathrm{~ms}$ with 50 sweeps and 3 replicates.

The instrument was calibrated in the range of 1$100 \mu \mathrm{gL}^{-1}$ using standards prepared by serial dilution of the Aristar $\mathrm{AgNO}_{3}$ solution in $0.1 \mathrm{M} \mathrm{HNO}_{3}$, and $10 \mu \mathrm{gL}^{-1}$ of ${ }^{115} \mathrm{In}$ was added to all samples and standards to correct for nebuliser- and plasma-related effects and for variations in sample viscosity. Between every ten samples, a calibration standard was analysed as a check, and if the recorded concentration deviated by more than $10 \%$ of its true concentration, the previous ten samples were re-analysed.

\subsection{Data Presentation and Analysis}

Concentrations of Ag measured in digests of the alga, faeces and tissues of L. littorina were normalised on a dry weight basis. Significant differences $(p<0.05)$ in mean sample masses or mean metal concentrations between samples arising from the different treatments or within the same treatment were ascertained by one-way analysis of variance using Minitab v15 following testing for homogeneity of variances and normality. Significant correlations $(p<0.05)$ between concentrations of $\mathrm{Ag}$ in the different tissues of L. littorina were identified using Microsoft Excel 2010.

\section{Results}

\subsection{Sea Water Ag Concentrations in the Treatments}

One of the major challenges in exposures involving direct comparisons between aqueous and nanoparticulate $\mathrm{Ag}$ is gaining similar experimental concentrations of the metal (Turner et al. 2012). This is because, firstly, addition of $\mathrm{AgNO}_{3}$ results in a time-dependent reduction in aqueous $\mathrm{Ag}$ concentration through the progressive adsorption of $\mathrm{Ag}^{+}$(and, possibly, $\mathrm{AgCl}^{0}$ ) to the aquarium surfaces, and, secondly, the rapid settlement of nanoparticles in the stock suspension immediately after sonication leads to an overestimation of the true quantity of $\mathrm{Ag}$ dispensed into the reactors.

We found that the addition of $30 \mu \mathrm{l}$ of the nanoparticle stock suspension and $150 \mu$ of the $\mathrm{AgNO}_{3}$ stock solution resulted in comparable concentrations of sea water Ag by the end of the 10day incubation period, as illustrated by our timedependent measurements of $\mathrm{Ag}$ throughout the treatments in Fig. 1. Specifically, addition of $10 \mu \mathrm{gL}^{-1}$ of aqueous $\mathrm{Ag}$ in $\mathrm{T} 1$ (contaminated sea water) and T2 (contaminated sea water and food) resulted in loss of metal to between about 2 and $3 \mu \mathrm{gL}^{-1}$ by the end of the exposures (that, quantitatively, could not be accounted for by accumulation of Ag by the macroalga or snail; see below). In T3 (contaminated food), the abrupt reduction in aqueous $\mathrm{Ag}$ after 5 days marks the transfer of the snail and contaminated algae to clean sea water in new aquaria; any $\mathrm{Ag}$ detected thereafter likely arises from the addition of a small quantity of contaminated water accompanying the transfer of the algal discs or the desorption or efflux of some metal from the discs when immersed in clean sea water.

Addition of $30 \mu \mathrm{l}$ of AgNP to the different treatments resulted in an initial measured concentration of Ag of around $2-3 \mu \mathrm{gL}^{-1}$. In $\mathrm{T} 1$ and $\mathrm{T} 2$, a moderate decline in Ag concentration was observed over the 10day period (that was only statistically significant in T2). Because measurements of Ag by ICP-MS do not distinguish aqueous and nanoparticulate $\mathrm{Ag}$, we cannot ascertain whether this decline is the result of some settlement of AgNP or the slow dissolution of Ag ions from the nanoparticles and their subsequent adsorption to the container surfaces. 
a

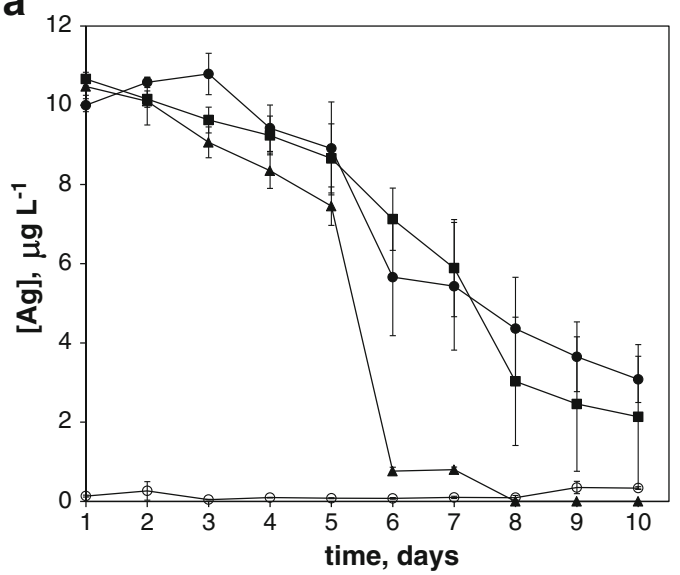

Fig. 1 Sea water concentrations of $\mathrm{Ag}$ in the control (empty circles) and in treatments T1 (filled circles), T2 (filled square) and T3 (filled triangles) as a function of time in exposures in

\subsection{Ag Concentrations in U. lactuca and in L. littorina} faeces

Figure 2 shows the dry-weight-normalised concentrations of Ag in the macroalga, U. lactuca (that is, the food for L. littorina), and in the pooled faeces produced by the snails in the different exposures. When added as aqueous $\mathrm{Ag}$, concentrations in U. lactuca after 5 days' exposure average about $100 \mu \mathrm{g} \mathrm{g}^{-1}$ and are statistically indistinguishable between T2 and T3. After 10 days, a significant decline in $\mathrm{Ag}$ concentration is observed that is consistent with the corresponding reduction in aqueous $\mathrm{Ag}$ shown in Fig. 1. Concentrations of Ag in the pooled faeces arising from T2 and T3 are similar to concentrations observed in the respective algal samples after 5 days' exposure. A considerably higher faecal concentration of Ag is, however, observed in T1 in which snails were exposed to contaminated water but no food.

When added as nanoparticles, concentrations of $\mathrm{Ag}$ in U. lactuca arising from $\mathrm{T} 2$ and $\mathrm{T} 3$ are lower than concentrations in the corresponding aqueous Ag exposures. Note that we are uncertain of the association of $\mathrm{Ag}$ with the alga arising from such exposures but previous evidence suggests it may well be simple adherence of particles at the algal surface (Turner et al. 2012). The concentration of $\mathrm{Ag}$ in the pooled faeces of $L$. littorina was higher than that in the corresponding food in $\mathrm{T} 2$ but similar to the concentration in food in T3. The concentration of Ag in the faeces arising from the absence of $U$. lactuca (T1) was greater than that arising from the presence of alga (T2 and T3) and remarkably b

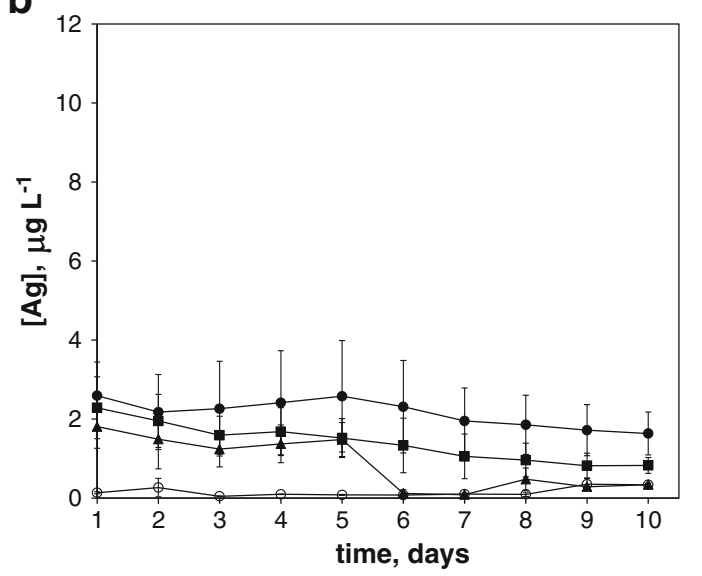

which the metal was added as a a solute and b nanoparticles; errors represent one standard deviation about the mean of 5 (control) or 8 (T1-T3) measurements

similar to the concentration observed when $\mathrm{Ag}$ was added in aqueous form in the corresponding treatment. Thus, although the quantity of faecal matter was lower in both aqueous and nanoparticle exposures of $\mathrm{T} 1$ (about $15 \mathrm{mg}$ ) than in $\mathrm{T} 2$ and $\mathrm{T} 3$ (about $25 \mathrm{mg}$ ), Ag appears to be more effectively constituted into faeces generated by feeding on aqueous nutrients and microscopic debris (through adsorption for example) than is accumulated by the macroalga. Of significance from an experimental perspective, the similarity in the Ag content of faeces generated in the absence of $U$. lactuca suggests that there was a comparable net quantity of $\mathrm{Ag}$ available to and processed by L. littorina in the aqueous and nanoparticulate exposures.

\subsection{Ag Concentrations in L. littorina}

The dry weights of L. littorina and component tissues thereof were not significantly different between treatments or exposures from the corresponding controls. Mean tissue weights were in the order: foot $>$ visceral mass $>$ head $>$ stomach $>$ gill, kidney; and the total dry weight of individual animals averaged about $120 \mathrm{mg}$. The concentrations of $\mathrm{Ag}$ measured in the different tissues of L. littorina are shown in Fig. 3; note that we have also computed total concentrations in the gastropod based on the weighted average of $\mathrm{Ag}$ concentrations in component tissues. In both controls and exposures, concentrations among replicates are more variable than in the alga, and in some cases, the standard deviation approaches the mean. Presumably, accumulation of Ag 


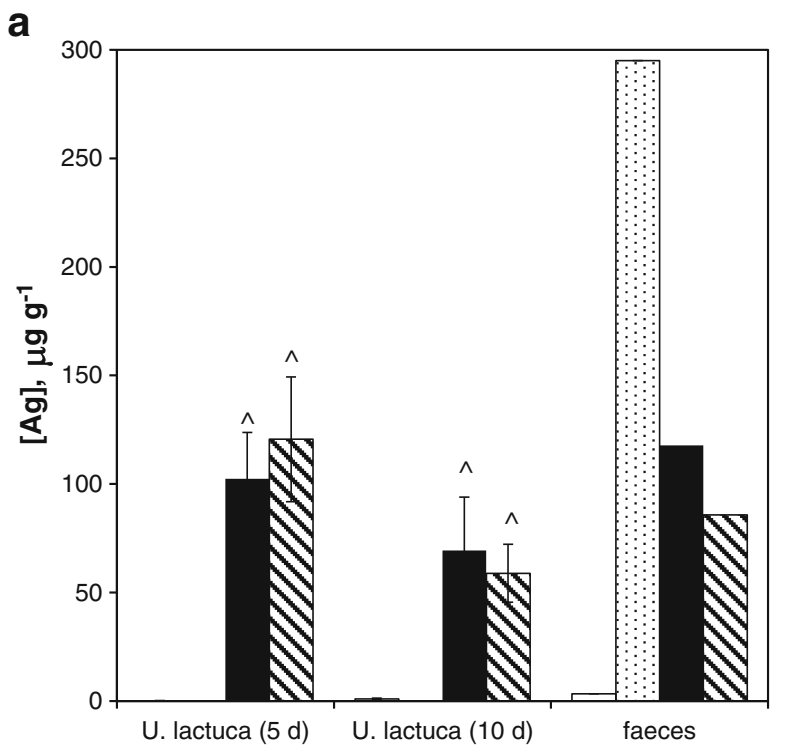

Fig. 2 Dry weight-normalised concentrations of $\mathrm{Ag}$ in Ulva lactuca, sampled after 5 and 10 days' incubation, and in pooled faeces remaining at the end of the exposure to the metal added as $\mathbf{a}$ a solute and $\mathbf{b}$ nanoparticles. From left to right, bars represent the control (white), and treatments T1 (stippled), T2

is a rather heterogeneous process that is sensitive to the precise size, condition and sex of individuals and, in the exposures involving $U$. lactuca at least, to the quantity of

a

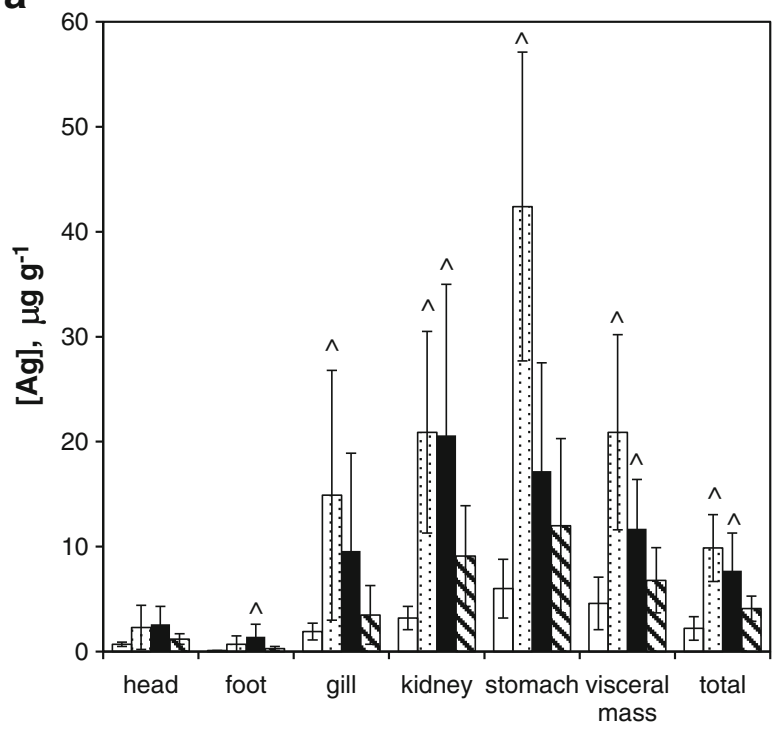

Fig. 3 Dry weight-normalised concentrations of $\mathrm{Ag}$ in the different compartments of Littorina littorina arising from exposure to Ag added as a a solute and $\mathbf{b}$ nanoparticles. From left to right, bars represent the control (white), and treatments T1 b

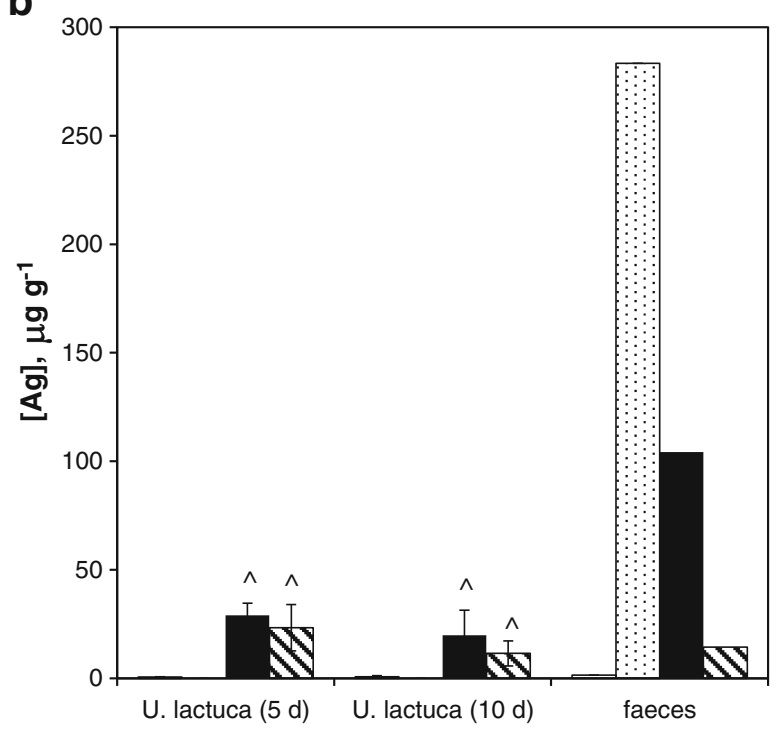

(solid) and T3 (hatched). Errors, shown for U. lactuca only, represent one standard deviation about the mean of 5 (control) or 8 (T1-T3) measurements; the hat symbol denotes a significant difference in mean concentration $(p<0.05)$ from the corresponding control

food consumed. In the controls, and based on mean concentrations, accumulation follows the order: visceral mass, stomach $>$ kidney $>$ gill $>$ head $>$ foot. In exposed

b

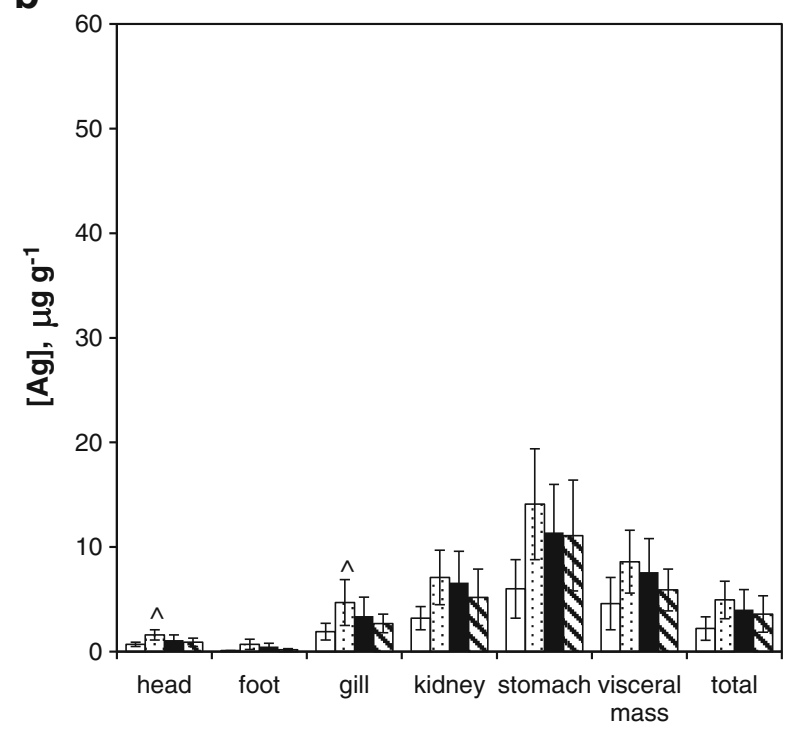

(stippled), T2 (solid) and T3 (hatched). Errors represent one standard deviation about the mean of 5 (control) or 8 (T1-T3) measurements; the hat symbol denotes a significant difference in mean concentration $(p<0.05)$ from the corresponding control 
individuals, and despite heterogeneous accumulation, significant measurable Ag uptake (relative to the controls) is evident when the metal is added in aqueous form. Specifically, accumulation occurs in T1 (contaminated sea water) in the gill, kidney, stomach and visceral mass, and in T2 (contaminated sea water and food) in the foot, kidney and visceral mass; accumulation is not, however, evident in any compartment in T3 (contaminated food). When added in nanoparticulate form, the concentration of $\mathrm{Ag}$ is only significantly greater than that in the corresponding control in the head and gill in T1.

Among the replicates in each exposure and treatment, significant relationships between Ag concentrations in different tissues were evident. Results of correlation analysis, summarised in Table 1, reveal that relationships were most abundant in $\mathrm{T} 1$ and $\mathrm{T} 2$ of the aqueous exposures, but were never observed in T3. Thus, where snails were exposed to contaminated water, the heterogeneity in $\mathrm{Ag}$ accumulation, noted above, appears to reflect heterogeneity among rather than within individual snails.

Despite little difference in concentrations from the corresponding controls, significant relationships were also observed in one or two cases each in T1, T2, and $\mathrm{T} 3$ of the nanoparticle exposures.

\section{Discussion}

The results of our study reveal that Ag is accumulated by the gastropod, L. littorina, when added in aqueous form and suggest that accumulation occurs principally from sea water rather than from ingested, pre- or co-contaminated algal food. Clearly, any Ag mobilised from U. lactuca in the digestive environment of L. littorina is not measurably

Table 1 Correlation matrix defining significant relationships ( $p$ $<0.05)$ between $\mathrm{Ag}$ concentrations in the different tissues of $L$. littorina $(n=8)$

\begin{tabular}{llllll}
\hline & head & foot & gill & kidney & stomach \\
\hline Foot & $\mathrm{T} 1, \mathrm{~T} 2, \mathrm{~T} 1$ & & & & \\
Gill & $\mathrm{T} 1, \mathrm{~T} 2$ & $\mathrm{~T} 1, \mathrm{~T} 2, \mathrm{~T} 1, \mathrm{~T} 2$ & & & \\
Kidney & $\mathrm{T} 2$ & $\mathrm{~T} 2$ & $\mathrm{~T} 2$ & & \\
Stomach & $\mathrm{T} 1, \mathrm{~T} 2$ & $\mathrm{~T} 1$ & $\mathrm{~T} 2$ & $\mathrm{~T} 1, \mathrm{~T} 2$ & \\
Visceral & $\mathrm{T} 2$ & & $\mathrm{~T} 2, \mathrm{~T} 3$ & $\mathrm{~T} 1, \mathrm{~T} 2$ & $\mathrm{~T} 2$ \\
mass & & & & & \\
\hline
\end{tabular}

$\mathrm{T} 1, \mathrm{~T} 2$ and $\mathrm{T} 3$ represent the different treatments exposed to aqueous $\mathrm{Ag}$ and, in italics, nanoparticulate $\mathrm{Ag}$ assimilated by the snail. Accumulation of metals from the dietary route has been observed in many marine herbivorous molluscs and fish (Chan et al. 2003; Blackmore and Wang 2004; Mulholland and Turner 2011). However, relative to other essential trace metals, the trophic transfer of Ag appears to be low in many marine animals (Abbe and Sanders 1990; Connell et al. 1991). This, at least partly, may be attributed to its high affinity for sulphurous ligands, which facilitates the uptake of Ag from the aqueous phase (see below) and binds it in a relatively inaccessible form in food materials (Fisher and Wang 1998).

The accumulation of $\mathrm{Ag}$ by L. littorina from the solute pathway may be attributed to the uptake of the free ion $\left(\mathrm{Ag}^{+}\right)$and, possibly, the moderately, hydrophobic, neutral chlorocomplex, $\mathrm{AgCl}^{0}$ (Reinfelder and Chang 1999; Wood et al. 2010), whose computed abundances in our culture medium, relative to total aqueous $\mathrm{Ag}$, are 0.002 and $0.57 \%$, respectively (Turner et al. 2012). The Ag ion is predicted to enter the snail through passive diffusion, a process that may be mediated by carrier molecules and maintained by a concentration gradient effected by Ag complexation with intracellular ligands. Silver has a very high affinity for sulphurcontaining ligands and complexation with metallothionein as a detoxification mechanism is known to occur in many molluscs, including L. littorina (Langston et al. 1998). Due to its low polarity, $\mathrm{AgCl}^{0}$ is likely to enter cells by diffusing across the lipid bilayer (Luoma et al. 1995). Our results indicate accumulation of $\mathrm{Ag}$ in the gill, kidney, stomach and visceral mass (including the digestive gland). Presumably, Ag is initially taken up from sea water by the gill via the epithelial cells and is subsequently transported via the haemolymph towards other specialised tissues, including the kidney and digestive gland (where metallothionein induction is most evident; Langston et al. 1998); here, the metal is stored, metabolised, detoxified or excreted.

In the present study, there was little measurable $\mathrm{Ag}$ accumulation by (or association with) L. littorina when the metal was introduced in nanoparticulate form. That $\mathrm{Ag}$ was only detected in the head and gill in one treatment suggests the association may well be a physical (adherent) one, with little subsequent means of Ag entering internal organs. The levels of Ag in U. lactuca and in the faeces of L. littorina clearly indicate throughput of $\mathrm{Ag}$ in the digestive system of the snail. However, comparison of $\mathrm{Ag}$ concentrations in faeces and corresponding alga suggest little release of AgNP or mobilisation of $\mathrm{Ag}$ from contaminated food. 
Silver added to freshwater in nanoparticulate form has been found to be taken up by a variety of aquatic organisms, including molluscs, crustaceans and fish (Kashiwada 2006; Lee et al. 2007; Ward and Kach 2009; Tao et al. 2009). However, due, in part, to technical challenges inherent in both imaging and quantifying AgNP at or within the membrane of an organism (Fabrega et al. 2011), the proposed mechanisms of $\mathrm{Ag}$ accumulation remain unclear and/or equivocal. The postulated, general routes of accumulation are centred around either endocytosis (or pinocytosis) or extracellular silver ion dissolution. The former mechanism involves the translocation of nanoparticles of between 1 and $100 \mathrm{~nm}$ in diameter by the invagination of the plasma membrane, the formation of vesicles that enclose the particles and the transport of the vesicle into the cell (Moore 2006; Asharani et al. 2008). The latter mechanism proceeds via an association of the nanoparticles with the surface of the membrane and the subsequent release of $\mathrm{Ag}^{+}$ions within the surface microlayers that are rapidly taken up (Jin et al. 2010; Liu and Hurt 2010).

Recent studies have also demonstrated trophic transfer of nanoparticles or metallic constituents thereof in laboratory mesocosms. For example, Ferry et al. (2009) reported accumulation of $\mathrm{Au}$ (from $\mathrm{Au}$ nanorods) in marine snails that grazed on contaminated biofilms, while Crouteau et al. (2011a) showed that Zn was efficiently assimilated by freshwater snails when fed $\mathrm{ZnO}$ nanoparticles in combination with diatoms. We are aware of two publications in which the trophic transfer of radiolabelled Ag added in both solute and nanoparticulate forms have been compared. Thus, Zhao and Wang (2010) fed the fresh water cladoceran, Daphnia magna, algae that had been pre-exposed to AgNP, and Crouteau et al. (2010b) fed the fresh water snail, Lymnaea stagnalis, a mixture of diatoms and AgNP. In both studies, accumulation (or, strictly, assimilation) of $\mathrm{Ag}$ was observed in all treatments and was faster when the metal was added as a solute than when added as nanoparticles; accumulation of Ag added as AgNP was greater in the presence of food in the former study and greater in the absence of food in the latter.

These observations are not wholly consistent with the findings of our study, and in particular those involving $\mathrm{Ag}$ derived from the addition of AgNP, although it must be appreciated that the radiotracer approach and analysis of whole individuals (rather than component tissues thereof) is likely a more sensitive means of examining accumulation. Lower accumulation of Ag by L. littorina overall may be attributed to the reduced bioavailability of the metal in sea water (relative to fresh water) where it is complexed to a significant extent by chloride ions. The $\mathrm{Ag}$ in the algal food we used in our experiment was also likely to be less bioavailable than in the studies above, where exposure of food to aqueous or nanoparticulate $\mathrm{Ag}$ was undertaken for a shorter period of time (12 or $24 \mathrm{~h}$ ) or was simply an algal-AgNP mixture. Given these discrepancies and the general lack of understanding of the biogeochemical behaviour and interactions of AgNP in the marine environment, further studies involving a broader range of organisms are recommended.

Acknowledgments We thank Andrew Atfield, Angela Harrop and Andy Fisher (UoP) for technical advice and assistance throughout this study. HL was funded by an Erasmus Mundus Joint European Masters scholarship.

\section{References}

Abbe, G. R., \& Sanders, J. G. (1990). Pathways of silver uptake and accumulation by the American oyster (Crassostrea virginica) in Chesapeake Bay. Estuarine, Coastal and Shelf Science, 31, 113-123.

Asharani, P. V., Wu, Y. L., Gong, Z. Y. \& Valiyaveettil, S. (2008). Toxicity of silver nanoparticles in zebra fish models. Nanotechnology, 19, article 255102

Bilberg, K., Malte, H., Wang, T., \& Baatrup, E. (2010). Silver nanoparticles and silver nitrate cause respiratory stress in Eurasian perch (Perca fluviatilis). Aquatic Toxicology, 96, 159-165.

Blackmore, G., \& Wang, W.-X. (2004). The transfer of cadmium, mercury, methylmercury and zinc in an intertidal rocky shore food chain. Journal of Experimental Marine Biology and Ecology, 307, 91-110.

Blaser, S. A., Scheringer, M., Macleod, M., \& Hungerbühler, K. (2008). Estimation of cumulative aquatic exposure and risk due to silver: contribution to nano-functionalized plastics and textiles. Science of the Total Environment, 390, 396-409.

Blinova, I., Ivask, A., Heinlaan, M., Mortimer, M., \& Kahru, A. (2010). Ecotoxicity of nanoparticles of $\mathrm{CuO}$ and $\mathrm{ZnO}$ in natural water. Environmental Pollution, 158, 41-47.

Bradford, A., Handy, R. D., Readman, J. W., Atfield, A., \& Mühling, M. (2009). Impact of silver nanoparticle contamination on the genetic diversity of natural bacterial assemblages in estuarine waters. Environmental Science and Technology, 43, 4530-4536.

Carlson, C., Hussain, S. M., Schrand, A. M., Braydich-Stolle, L. K., Hess, K. L., Jones, R. L., et al. (2008). Unique cellular interaction of silver nanoparticles: size-dependent generation of reactive oxygen species. Journal of Physical Chemistry, 112, 13608-13619.

Chan, S. M., Wang, W.-X., \& Ni, I. H. (2003). The uptake of Cd, $\mathrm{Cr}$, and $\mathrm{Zn}$ by the macroalga Enteromorpha crinita and 
subsequent transfer to the marine herbivorous rabbitfish, Siganus canaliculatus. Archives of Environmental Contamination and Toxicology, 44, 298-306.

Connell, D. B., Sanders, J. G., Riedel, G. F., \& Abbe, G. R. (1991). Pathways of silver uptake and trophic transfer in estuarine organisms. Environmental Science and Technology, 25, 921-924.

Crouteau, M. N., Dybowska, A. D., Luoma, S. N., \& ValsamiJones, E. (2011a). A novel approach reveals that zinc oxide nanoparticles are bioavailable and toxic after dietary exposure. Nanotoxicology, 5, 79-90.

Crouteau, M. N., Misra, S. K., Luoma, S. N., \& Valsami-Jones, E. (2011b). Silver bioaccumulation dynamics in a freshwater invertebrate after aqueous and dietary exposures to nanosized and ionic Ag. Environmental Science and Technology, 45, $660-6607$.

Fabrega, J., Luoma, S. N., Tyler, C. R., Galloway, T. S., \& Lead, J. R. (2011). Silver nanoparticles: behaviour and effects in the aquatic environment. Environment International, 37, 517-531.

Ferry, J. L., Craig, P., Hexel, C., Sisco, P., Frey, R., Pennington, P. L., et al. (2009). Transfer of gold nanoparticles from the water column to the estuarine food web. Nature Nanotechnology, 4, 441-444.

Fisher, N. S., \& Wang, W. X. (1998). Trophic transfer of silver to marine herbivores: a review of recent studies. Environmental Toxicology and Chemistry, 17, 562-571.

Gottschalk, F., Sonderer, T., Scholz, R. W., \& Nowack, B. (2009). Modeled environmental concentrations of engineered nanoparticles $\left(\mathrm{TiO}_{2}, \mathrm{ZnO}, \mathrm{Ag}, \mathrm{CNT}\right.$, fullerenes) for different regions. Environmental Science and Technology, 43, 8113-8118.

Hao, L. H., Wang, Z. Y., \& Xing, B. S. (2009). Effect of sub-acute exposure to $\mathrm{TiO}_{2}$ nanoparticles on oxidative stress and histopathological changes in juvenile carp (Cyprinus carpio). Journal of Environmental Sciences, 21, 1459-1466.

Jin, X., Li, M., Wang, J., Marambio-Jones, C., Peng, F. B., Huang, X. F., et al. (2010). High-throughput screening of silver nanoparticle stability and bacterial inactivation in aquatic media: influence of specific ions. Environmental Science and Technology, 44, 7321-7328.

Kashiwada, S. (2006). Distribution of nanoparticles in the seethrough medaka (Oryzias latipes). Environmental Health Perspectives, 114, 1697-1702.

Köhler, A. R., Som, C., Helland, A., \& Gottschalk, F. (2008). Studying the potential release of carbon nanotubes throughout the application life cycle. Journal of Cleaner Production, 16, 927-937.

Langston, W. J., Bebianno, M. J., \& Burt, G. R. (1998). Metal handling strategies in molluscs. In W. J. Langston \& M. J. Bebianno (Eds.), Metal metabolism in aquatic environments (pp. 219-283). London: Chapman and Hall.

Lee, K. J., Nallathamby, P. D., Browning, L. M., Osgood, C. J., \& Xu, X. H. N. (2007). In vivo imaging of transport and biocompatibility of single silver nanoparticles in early development of zebrafish embryos. ACS Nano, 1, 133-143.

Liu, J., \& Hurt, R. H. (2010). Ion release kinetics and particle persistence in aqueous nano-silver colloids. Environmental Science and Technology, 44, 2169-2175.
Luoma, S. N., Ho, Y. B., \& Bryan, G. W. (1995). Fate, bioavailability and toxicity of silver in estuarine environments. Marine Pollution Bulletin, 31, 44-54.

MacKay, C. E., Johns, M., Salatas, J. H., Bessinger, B., \& Perri, M. (2006). Stochastic probability modeling to predict the environmental stability of nanoparticles in aqueous suspension. Integrated Environmental Assessment and Management, 2, 293298.

Miao, A. J., Schwehr, K. A., Xu, C., Zhang, S. J., Luo, Z., Quigg, A., et al. (2009). The algal toxicity of silver engineered nanoparticles and detoxification by exopolymeric substances. Environmental Pollution, 157, 3034-3041.

Moore, M. N. (2006). Do nanoparticles present ecotoxicological risks for the health of the aquatic environment? Environment International, 32, 967-976.

Mulholland, R., \& Turner, A. (2011). Accumulation of platinum group elements by the marine gastropod Littorina littorea. Environmental Pollution, 159, 977-982.

Nowack, B., \& Bucheli, T. D. (2007). Occurrence, behavior and effects of nanoparticles in the environment. Environmental Pollution, 150, 5-22.

Park, S. J., Park, Y. C., Lee, S. W., Jeong, M. S., Yu, K. N., Jung, H., et al. (2011). Comparing the toxic mechanism of synthesized zinc oxide nanomaterials by physicochemical characterization and reactive oxygen species properties. Toxicology Letters, 207, 197-203.

Reinfelder, J. R., \& Chang, S. I. (1999). Speciation and microalgal bioavailability of inorganic silver. Environmental Science and Technology, 33, 1860-1863.

Ringwood, A. H., McCarthy, M., Bates, T. C., \& Carroll, D. L. (2010). The effects of silver nanoparticles on oyster embryos. Marine Environmental Research, 69, S49-S51.

Tao, X., Fortner, J. D., Zhang, B., He, Y. H., Chen, Y. S., \& Hughes, J. B. (2009). Effects of aqueous stable fullerene nanocrystals (nC(60)) on Daphnia magna: evaluation of sub-lethal reproductive responses and accumulation. Chemosphere, 77, 1482-1487.

Turner, A., Brice, D., \& Brown, M. T. (2012). Interactions of silver nanoparticles with the marine macroalga, Ulva lactuca. Ecotoxicology, 21, 148-154.

Ward, J. E., \& Kach, D. J. (2009). Marine aggregates facilitate ingestion of nanoparticles by suspension-feeding bivalves. Marine Environmental Research, 68, 137-142.

Wood, C. M., Grosell, M., McDonald, M. D., Playle, R. C., \& Walsh, P. J. (2010). Effects of waterborne silver in a marine teleost, the gulf toadfish (Opsanus beta): effects of feeding and chronic exposure on bioaccumulation. Aquatic Toxicology, 99, 138-148.

Zhao, C. M., \& Wang, W. X. (2010). Biokinetic uptake and efflux of silver nanoparticles in Daphnia magna. Environmental Science and Technology, 44, 7699-7704.

Zhu, X. S., Zhu, L., Lang, Y. P., \& Chen, Y. S. (2008). Oxidative stress and growth inhibition in the freshwater fish Carassius autatus induced by chronic exposure to sublethal fullerene aggregates. Environmental Toxicology and Chemistry, 27, 1979-1985. 